\title{
A SÃo paUlo das tramas
}

NAS TRAMAS DA CIDADE: TRAJETÓRIAS URBANAS E SEUS TERRITÓRIOS,

de Vera da Silva Telles e Robert Cabanes (orgs.). São Paulo: Associação Editorial Humanitas, 2006.

FRAYA FREHSE

Se as cidades têm sido objetos privilegiados da sociologia desde os primórdios da disciplina, a história desta em cada país se constituiu, em boa parte, a partir da seleção de cidades bem específicas como referências empíricas para a reflexão sociológica. $\mathrm{Na}$ Alemanha, um cenário urbano privilegiado foi sobretudo Berlim; na França, Paris; na Inglaterra, Londres; nos Estados Unidos, Chicago. E isso, em meio a motivações variadas, político-institucionais, intelectuais e mesmo geográficas (muitas vezes, situavam-se nessas cidades as universidades onde a disciplina começou a ganhar espaço institucional). No Brasil, não foi diferente. Como disciplina acadêmica, a sociologia adentrou as instituições de ensino superior, na década de 1930, debruçando-se com interesse sobre São Paulo. O que não surpreende, pois foi nessa cidade que se instalaram a Escola Livre de Sociologia e Política (1933) e a Faculdade de Filosofia, Ciências e Letras (1934).

Esse foi apenas o início de uma longa história, no seio da sociologia brasileira. Ela evidentemente não se restringiu a estudos sobre São Paulo, porém foi, pouco a pouco, assegurando para essa urbe o papel não somente de laboratório de investigação empírica revisitado com freqüência, mas de problema próprio de pesquisa, redefinido ao longo do tempo. Uma evidência da vitalidade dessa história, neste início de século XXI, é Nas tramas da cidade: trajetórias urbanas e seus territórios, volume de oito capítulos organizado pela socióloga brasileira Vera da Silva Telles e pelo sociólogo francês Robert Cabanes. Assumindo como pressuposto as transformações econômicas, políticas e socioespaciais em São Paulo, sobretudo a partir da década de 1990, os autores da coletânea - além de Telles e Cabanes, os pós-graduandos Daniel Veloso Hirata, Eliane Alves da Silva e José Cesar de Magalhães Jr., orientandos da organizadora - empenham-se em enfrentar, a partir de ângulos variados mas nem por isso incompatíveis, a questão de "como os processos em curso redefinem a dinâmica societária, a 
ordem das relações sociais e suas hierarquias, as mediações sociais e o jogo dos atores, as práticas urbanas e os usos da cidade" (p.13).A problemática, anunciada na "Introdução", confere ao livro o estatuto de capítulo recente de um questionamento que de fato há muito se faz presente na sociologia que reflete sobre a cidade de São Paulo: como se estabelecem - e se modificam - as relações sociais na cidade em meio às aceleradas mudanças históricas respectivamente em curso ${ }^{1}$ ? $\mathrm{E}$ uma pergunta que, na verdade, faz todo o sentido considerando-se que contundentes mudanças econômicas, políticas, urbanísticas, sociais e culturais não têm faltado em São Paulo, no mínimo desde as primeiras pesquisas propriamente sociológicas sobre a cidade.

Situar Nas tramas da cidade nesse já duradouro entremeado de fios interpretativos que compõem a sociologia concentrada no estudo da cidade de São Paulo não significa, contudo, que estamos diante de "mais do mesmo". Já as trajetórias intelectuais dos organizadores indicam que as tramas, aqui, são outras... Telles nelas se enredou na esteira de uma consolidada reflexão teórica e metodológica sobre a pobreza, o trabalho, a cidadania e os vínculos entre os três; Cabanes, por sua vez, tem um longo percurso de reflexões sobre gestão democrática e trajetórias ocupacionais em cidades brasileiras. Se, para cada um, São Paulo é há tempos um cenário empírico referencial de pesquisa, parece-me que é notadamente na parceria materializada neste livro que essa cidade se torna um problema teórico-metodológico específico a ser enfrentado. Assim, o encontro com essa história a que aludi anteriormente se faz inevitável; e o resultado desse encontro, pleno de originalidade.

Uma novidade que o livro traz para o debate sociológico sobre São Paulo é a construção teórico-metodológica elaborada para compreender as novas relações sociais urdidas na paisagem urbana alterada pelas mudanças que atingiram Estado, economia e sociedade no decorrer da última década. Se, como enfatiza a "Introdução", a coletânea propõe-se como "percurso exploratório" (p. 14), o trajeto efetivamente aproxima o leitor dos fundamentos de um "método de pensar" - para relembrar Pierre Bourdieu ${ }^{2}$ - original sobre a complexidade da São Paulo do presente. E, considerando-se o histórico de engajamento político dos organizadores, há como complementar que se trata de um "método de pensar" que necessariamente conta com uma interface crítica de cunho político em relação à chamada "desregulação neoliberal em tempos de globalização, financeirização da economia e revolução tecnológica" (p.43).

É fato que os autores justificam a originalidade de sua abordagem de outra forma. Para eles, a própria pergunta pelo conhecimento da "dinâmica societária" seria inusitada, no debate acadêmico sobrea São Paulo da atualidade. O primeiro capítulo do livro ("Debate: a cidade
[1] Sobre os primórdios desse debate acadêmico, referido a São Paulo de finais do século XIX, ver Frehse, Fraya. Otempo das ruas na São Paulo de fins do Império. São Paulo: Edusp, 2005, pp. 45-84.
[2] Cf. Bourdieu, Pierre. "Introdução a uma sociologia reflexiva [1987]". In: O poder simbólico. Trad. Fernando Tomaz. Lisboa/Rio de Janeiro: Difel/ Bertrand Brasil, 1989, p. 20. 
como questão"), redigido por Telles, situa justamente a questão do livro em relação a algumas das perspectivas sociológicas atualmente mais difundidas acerca do mundo social na cidade ao longo dos últimos trinta anos. Telles remete-se em especial à sociologia, não se referindo a reflexões antropológicas sobre o mundo social paulistano atual, que têm se multiplicado. Partindo da "notável" quantidade e qualidade das informações empíricas disponíveis sobre a vulnerabilidade social e a expansão urbana do presente (p. 6o), a autora busca compreender o "entramado social" forjado pelas mudanças recentes nas relações entre trabalho, cidade e Estado escapando tanto a modelos explicativos referenciados pelos pares conceituais centro-periferia, trabalho-moradia, mercado formal-mercado informal, quanto a caracterizações da pobreza em torno das noções de "exclusão social" e de "segregação urbana". Para tanto, o objetivo desdobra-se em "três ordens de questões": uma de cunho empírico, referida ao mundo social em transformação; uma de cunho político, relativa à "ampliada e crescente zona de indiferenciação entre o lícito e o ilícito, o direito e o não-direito, entre o público e o privado, a norma e a exceção" na atual dinâmica societária; enfim, uma questão teórico-metodológica sobre a possibilidade de transcender o "já-dito" sobre a cidade (pp. 53-4). A meu ver, o todo de Nas tramas da cidade constitui uma resposta original, em termos metodológicos, justamente a essas três questões.

O capítulo "Debate: a cidade como questão" integra a primeira parte ("Pontos e linhas") do livro ao lado de "Trajetórias urbanas: fios de uma descrição de cidade", também redigido por Telles e certamente o mais complexo da obra. Neste capítulo, a autora alinhava as orientações teóricas que, provindas sobretudo do cenário acadêmico francês, a auxiliam a argumentar que "trajetórias biográficas" de indivíduos e suas famílias, moradores de bairros pobres do meridional distrito do Jardim São Luís e do oriental distrito de Guaianazes, são passíveis de revelar "perfis" múltiplos de cidade. Estes, por sua vez, se insinuariam em meio às "tramas" das quais a própria cidade se constituiria, por ser feita - e aqui a autora recorre a Bernard Lepetit - de "cruzamentos" contemporâneos de práticas, hábitos, comportamentos e histórias de tempos e espaços diversos (p. 74). Em jogo estão trajetórias ligadas a deslocamentos e agenciamentos cotidianos que membros de distintas gerações dessas famílias empreenderam nas décadas de 1970 e 1980 e entre 2001 e 2004 em busca de moradia, de trabalho e para articular ambos com os serviços urbanos. Apreendidas por meio de "entrevistas biográficas" (p.19), essas trajetórias, embora individuais, seriam reveladoras de dinâmicas societárias mais abrangentes.

Telles não deixa explícito que as trajetórias urbanas ocultariam um peculiar "método de pensar" a cidade. No entanto é, a meu ver, disso mesmo que se trata. Para a autora, as trajetórias integram "eventos de 
mobilidade" urbana que podem ser situados nos tempos e espaços em que as histórias contadas pelos entrevistados se desenrolam. Sob esse prisma, esses eventos constituem "pontos de condensações de tramas sociais que articulam histórias singulares e destinações coletivas" (p. 69).É que, imbuídos de tempo e espaço, eles seriam atravessados por três "linhas de intensidade": a "linha vertical das cronologias" (que articulam os tempos biográficos e os sociais); a "linha horizontal das espacialidades" (em que os tempos se realizam); e, perpassando tudo, "a linha perpendicular dos eventos políticos", que, oriundos de tempos distintos, conectam espaços com os tempos políticos da cidade. Com base na descrição de percursos individuais e familiares, seria, assim, possível reconstituir "territórios" de práticas e conexões configuradoras de bloqueios e possibilidades implícitos a "diagramas diferenciados de relações conforme as regiões da cidade, as situações de vida e os tempos sociais cifrados em seus espaços" (p. 71). Como os territórios transportam as trajetórias para um mesmo "plano de atualidade" (p. 74), haveria como confrontar experiências e situações vivenciadas nos diferentes territórios e assim discernir, no "entremeio" das particularidades das situações, os "focos de tensão" da cidade referidos particularmente à produção do espaço urbano; aos vínculos entre trabalho e cidade; ao papel da violência no "fluxo" das mobilidades cotidianas e, assim, nas tramas de que se compõe a experiência da cidade. Em questão estão "possibilidades (e bloqueios) para os indivíduos transformarem bens e recursos em 'formas valiosas de vida'", nos termos de Giorgio Agamben3; isto é, como sintetiza a autora em outro momento de Nas tramas da cidade, a "capacidade de inventar outros possíveis" ( $\mathrm{p}$.373).

Do constructo teórico-metodológico resulta como estratégia narrativa, mais detalhada no segundo capítulo, a descrição. Ela responderia não apenas à exigência de expor a contemporaneidade dos territórios constituídos com base nas conexões existentes entre os tempos biográficos, políticos e as temporalidades urbanas, como abriria espaço para novas questões, o que coaduna com o espírito exploratório do empreendimento. Telles fornece uma breve amostra das potencialidades interpretativas de seu método no próprio capítulo, confrontando as trajetórias de cinco "personagens" ligadas respectivamente ao universo de perueiros e de motoqueiros nas zonas Leste e Sul.

Mas é na segunda parte ("Cenas urbanas, histórias e seus personagens") que o contato do leitor com o universo empírico da pesquisa se intensifica. E não somente textual, como visualmente. A primeira parte do livro é arrematada por uma primeira série de fotografias aéreas não legendadas, de autoria de Jorge Hirata, que podem ser associadas às duas regiões em foco.A seguir, cada um dos capítulos éintroduzido por quatro páginas contendo fotografias aéreas, além de outras
[3] Agamben, G.Homo sacer. Opoder soberano e a vida nua. Trad. Henrique Búrigo. Belo Horizonte: Editora da UFMG, 2003. 
imagens não legendadas, agora de Fábio Braga, que parecem referir-se às regiões tematizadas no respectivo capítulo. São vistas (em alguns casos, belas) de ruas, do interior de casas, quintais e lajes. E são ainda, às vezes, flagrantes de indivíduos jogando futebol de várzea, movendo-se por alguma feira, conversando dentro de casa. Dispostas como estão, as imagens conectam entre si ângulos distintos de apreensão fotográfica de duas regiões igualmente vulneráveis, em termos sociais. As fotografias são ainda mediações que articulam os textos de cada capítulo com as imagens e entre si, colaborando a seu modo para a amarração da trama que é o livro.

Instigado pelo provocador silêncio das fotografias, o leitor se depara, nos textos de cada capítulo, com uma pletora de inquietantes ruídos empíricos provenientes dos territórios construídos através do método. São, no capítulo 3 ("Nas franjas da 'cidade global': tudo certo, tudo em ordem?"), também escrito por Telles, os percursos habitacionais e de trabalho de gerações distintas de duas famílias de migrantes nordestinos na Vila Marinalva, situada entre a abastada "cidade global" e a sua periferia sul, entre as décadas de 1970 e 2000 . No capítulo 4 ("Ao lado, o outro lado: veredas incertas"), redigido por Telles, Hirata e Magalhães Jr., entram em cena, por referência ao mesmo período histórico, as trajetórias ocupacionais, disputas espaciais e pela sociabilidade ligada ao futebol de várzea em uma favela contígua à Vila Marinalva. É então, no capítulo 5 ("No meio do campo: o que está em jogo no futebol de várzea?"), a vez de um estudo concentrado especificamente nas tramas sociais em que se insere o futebol de várzea praticado nas regiões Sul e Leste. Do ponto de vista da trama narrativa que amarra o conjunto, não poderia haver melhor lugar para esse texto, versão modificada de um capítulo da dissertação de mestrado de Hirata: no meio do livro aparece o "meio-decampo" que permite a construção de um território no qual, ao mesmo tempo em que se conectam as trajetórias de dois organizadores de times de futebol de várzea, nas duas regiões entre as décadas de 1980 e 2000 , elas se separam indelevelmente. Depois do "meio-do-campo", os dois capítulos subseqüentes abordam trajetórias do leste da cidade. Em um primeiro momento ("No outro extremo da cidade: 'Aqui é tudo ocupação'”), Telles reconstrói trajetórias urbanas em torno da recémocupada Vila Diana, no centro de Guaianazes, e das percepções díspares que membros da família de um morador-militante têm de sua própria trajetória habitacional. Já no sétimo capítulo ("Territórios em disputa: a produção do espaço em ato"), a autora e Silva buscam a trama de relações ecircunstâncias que "produzem o espaço em ato", por meio das histórias de moradores que participaram, em 2001, da dramática ocupação do Jardim São Carlos, também no centro de Guaianazes.

Se a estrutura argumentativa da segunda parte do livro é fortemente tributária do "método de pensar" explicitado por Telles, a ter- 
ceira e última parte da obra ("Os lugares da família"), composta de um capítulo, abre espaço para uma trama diferente. Em "Espaço privado e espaço público: o jogo de suas relações", de Cabanes, a personagem coletiva que perpassa o livro todo, a família, torna-a ponto de articulação entre o espaço privado e o público, a ser desvendada mediante um método peculiar. O autor interessa-se pelas "interpretações" a que membros das últimas duas gerações de "famílias 'operárias e populares'” (p. 389) em São Paulo, entre o final da década de 1980 e o momento atual, submetem as "formas de individuação impostas pelo espaço público econômico" em meio à "ruptura neoliberal dos anos 90" (p. 400). O objetivo é avaliar como as mudanças no interior da família incidem sobre os vínculos entre o espaço privado, "de relativa autonomia capaz de vincular as articulações interativas com os espaços públicos" (p.396), e esses mesmos espaços públicos. Para tanto, cabe "descrever e analisar" especificamente três temáticas referentes às interações dos indivíduos e de suas famílias no espaço privado: "a produção de si, a interação conjugal, a relação de filiação"; ademais, vale examinar "os tipos de narrativas e de ação, no âmbito das capacidades de cada um dos atores" (p.400).

Dotado dessas características, o problema de pesquisa assume contornos distintos daquele que perpassou os capítulos anteriores. As narrativas contemplam assuntos específicos (além de transformações no trabalho, a "democracia local", a esfera religiosa, a infiltração do narcotráfico na vida familiar). E a economia do texto também é peculiar, não referenciando o universo empírico contemplado na investigação.

De todo modo, o fato de estarem em foco os planos e destinos das famílias "operárias e populares" dá ao capítulo certo caráter de síntese de padrões de relacionamento presentes nos demais capítulos. Isso, até que a "Conclusão" forneça outra síntese, agora em torno de três perguntas de cunho teórico que, no meu entender, retomam sob um ângulo novo, enriquecido pelos resultados do percurso analítico, as três questões específicas anunciadas na "Introdução". O questionamento empírico do início pode agora ser equacionado em termos de "Novas mediações, novo diagrama de relações: gestão da pobreza, uma outra 'invenção do social'?". A questão sobre o lugar da política abre espaço para o desafio de enfrentar as "Novas ilegalidades e as flores do mal: no jogo de luz e sombra entre o lícito e o ilícito, defesa da vida e das formas de vida?". Já a questão teórico-metodológica sobre a possibilidade do ainda não-dito encontra respostas na "Experiência do trabalho, experiência urbana: onde ouvir os rumores da cidade?".

Alinhavada em torno desse bem estruturado "entramado" textual e fotográfico, a coletânea conta com uma complexidade teórico-metodológica, empírica e interpretativa que dificilmente tem como encontrar 
[4] Bourdieu, op.cit., p. 20.

[5] Cf. Canclini, Néstor García e outros. La ciudad de los viajeros. Travesías e imaginarios urbanos: México, 1940-2000. Ciudad de México: Grijalbo/Universidad Autónoma de México, 1996.

[6] Cf.,entre outros,Martins,José de Souza de. Exclusão social e a nova desigualdade. São Paulo: Paulus, 1997; e $A$ sociedade vista do abismo. Petrópolis: Vozes, 2002. abrigo nos limites de um texto como este. Interessa aqui, antes, chamar a atenção para o empenho intelectual que essa complexidade oculta: justo o de,em um mesmolivro, construir teoricamentee submeter dados empíricos a um original "método de pensar" a "dinâmica societária" engendrada em São Paulo pelas transformações históricas recentes.

É um "método de pensar" dotado de algo que o torna um exemplo daquilo que, novamente recorrendo à reflexão de Bourdieu, constitui a "arte", nas ciências sociais: a sua "eficácia" em "constituir objetos socialmente insignificantes em objetos científicos ou, o que é o mesmo, na sua capacidade de reconstruir cientificamente os grandes objetos socialmente importantes, apreendendo-os de um ângulo imprevisto" 4 . Ao submeterem "mobilidades urbanas" ao seu método, os autores demonstram que a variedade empírica desse objeto tem potencialidades interpretativas também para a sociologia devotada à São Paulo atual - e não somente para uma antropologia concentrada na cidade que a circulação de pessoas e de veículos pelo espaço urbano traz para o primeiro plano5. Nesse sentido, Nas tramas da cidade engrossa, só que de modo original, conectando metodologicamente "trajetórias" a "territórios", o rol das abordagens sociológicas - algumas delas, como a de Joseph e de Harvey, mencionadas no próprio livro (pp. 75-6) - que refletem sobre a cidade em termos de circulação e acessibilidade.

Vale sublinhar, por outro lado, que, retirando da "insignificância" as "mobilidades urbanas", os autores oferecem efetivamente, ao debate acadêmico sobre a São Paulo do presente, um "ângulo imprevisto" para a reconsideração de objetos de grande importância social como "exclusão social" e "segregação urbana". Ao explorar empiricamente toda a riqueza interpretativa do entre - entre regiões da cidade, entre bairros, entre famílias, entre indivíduos de uma ou distintas gerações no interior de uma mesma família ou em famílias diferentes, "entre formas novas e velhas de clientelismo e tutelagens, disputas abertas e subterrâneas por recursos e poder nos agenciamentos locais, e também práticas associativas entre a gestão da pobreza e outros sentidos da política" (p.435) -, o livro deixa entrever contrapontisticamente como são pobres as pontas (dicotômicas e fixas, por isso mesmo excludentes e segregadoras) da teia. Argumentando nesses termos, Nas tramas da cidade engrossa também, a partir de outros referenciais teóricos, o rol das críticas à caracterização da pobreza urbana atual em termos de "exclusão" 6 .

Mas as "mobilidades" viabilizam mais, em termos interpretativos. Expondo as dificuldades que envolveriam a noção de "cidadania local" atualmente, associada, com freqüência, a uma presentista "gestão do social" ( $p .76$ ), elas permitem repensar o que significa mesmo o "direito à cidade" de Henri Lefebvre nos dias de hoje; e questionar onde se situam as possibilidades históricas, "possíveis" lefebvrianos, nesse sentido. 
Outro "grande objeto socialmente importante" passível de ser repensado a partir do "ângulo" proposto pela coletânea é a noção de trabalho. Centrando-se nas conexões deste com o espaço e a cidade, a pesquisa demonstra empiricamente que ele, embora em boa parte uma virtualidade nesses tempos de desemprego, medeia de forma privilegiada os laços de pertencimento que o morador estabelece com a própria família, o bairro, a cidade.

E o leitor se pergunta como ficaria o equacionamento entre espaço, trabalho e cidade se a análise incorporasse variáveis como educação, por exemplo, ou lazer, atualmente importantes inclusive entre os segmentos mais pobres da população. Tal possibilidade é implícita à noção de "eventos de mobilidade", compostos também dos "deslocamentos cotidianos que articulam trabalho, moradia e serviços urbanos" (p.69).

Especificamente quanto à "dinâmica societária" nos tempos atuais, a interpretação resulta na ênfase em "uma ampliada e crescente zona de indiferenciação entre o lícito e o ilícito, o direito e o não-direito, entre o público e o privado, a norma e a exceção, projetando uma inquietante linha de sombra no conjunto da vida urbana e suas formas políticas" (pp. 53 e 436). Recorrendo, para tal formulação, ao Agamben de Homo sacer, os autores dão a entender que a realidade atual envolve a elaboração de estratégias em busca de "formas de vida" que escapam à política. A demonstração empírica mais cabal do argumento é fornecida pelo capítulo 7, em que Telles decupa retrospectivamente a ocupação do Jardim São Carlos, a fim de apreender as variáveis — alheias à política que interferiram na produção daquele espaço "em ato".

Contemplado sob o prisma filosófico-político de Agamben, o "entremeio social" paulistano é instantaneamente inserido em uma dinâmica sociopolítica de uma abrangência que é internacional nos dias de hoje. E, de fato, afirmam os autores que a "zona de indiferenciação" se aplica à "cidade" como "campo de práticas" (p.62), nos termos de Marcel Roncayolo; à cidade em geral, portanto, o que retira de São Paulo qualquer especificidade.

Em face de tal formulação, a questão que fica diz respeito ao lugar das singularidades da realidade urbana brasileira ou, no mínimo, paulistana. O quanto será que a "zona de indiferenciação" flagrada pelos autores não deve a toda uma história brasileira de longa duração de convivência costumeira entre o lícito e o ilícito, o público e o privado, o formal e o informal? O pensamento social brasileiro conta com célebres teses a esse respeito7. À luz de referências como essas, o "entramado social" exposto pela coletânea é talvez exemplar sobretudo de transformações recentes dessa velha dinâmica sociocultural, em cidades brasileiras como São Paulo.

Se a qualidade e o encadeamento narrativo dos argumentos teóricos e empíricos viabilizam essas e outras possibilidades interpretati-
[7] Cf. a respeito, entre outros, Candido, Antonio. "Dialética da malandragem". In: O discurso e a cidade. São Paulo: Duas Cidades, 1993 [1970], pp. 19-54; Roberto DaMatta, Carnavais, malandros e heróis. $6^{\text {a }}$ ed. Rio de Janeiro: Rocco, 1997 [1979]. 
[8] Cf. Geertz, C. "Blurred genres: the refiguration of social thought". In: Local knowledge. Further essays in interpretive anthropology. Nova York: Basic Books, 1983 [1980], p. 22. vas, além de exporem um "método de pensar" original, o uso de um número, a meu ver, demasiado de "analogias explanatórias" — relembrando Clifford Geertz ${ }^{8}$ — conturba um tanto a explicitação dos argumentos. As analogias provêm de manifestações culturais ("atores em disputa" remetem a teatro e a jogo; "tramas" e seus "entremeios", à arte da tecelagem) e da ciência - no caso, em especial da física (com suas "linhas de força", "campos de gravitação" e "fluxos"). Perscrutar a presença dessas analogias no livro deixa intuir um peso teórico-metodológico distinto para as diversas analogias explicativas que valeria a pena ser explicitado, a fim de facilitar a compreensão da construção metodológica empreendida.

Não obstante os riscos desse recurso narrativo, o emprego da descrição é rico de potencialidades cognitivas. Ela oferece preciosos dados de cunho etnográfico sobre as relações e representações sociais vigentes no seio de famílias migrantes moradoras nos limiares meridionais e orientais da "cidade global". O trecho de uma longa entrevista biográfica com Inês, a filha de um militante desempregado da Vila Diana, é emblemática nesse sentido: "Estes dias eu estava passando na viela [do bairro em que mora] e as crianças estavam brincando de polícia e ladrão. Antigamente a gente brigava para ser o polícia que ia pegar o ladrão. Hoje em dia não, elas brigam para ser o ladrão" (p.312). E haveria ainda como apontar dados reveladores de lógicas de relacionamento não restritas aos contextos empíricos tematizados. Assim, por exemplo, a inspirada referência àquilo que Telles chama de "financeirização do popular "fiado'" (p.40) através dos cartões de financiamento oferecidos pelos hipermercados queladeiam o Jardim São Luís; ou a esclarecedora explanação de Hirata sobre o código de ética "L.H.P.", "Lealdade, Humildade, Procedimento" (pp. 275-8), um conjunto de regras de conduta para "sobreviver na adversidade" atualmente muito difundidas no futebol de várzea, nas torcidas organizadas e no interior dos presídios. Esses e outros detalhes empíricos asseguram ao livro um lugar de destaque no conjunto das etnografias urbanas recentes sobre a dinâmica urbana paulistana.

Cabe salientar que a efervescência etnográfica da coletânea apenas se potencializaria com uma formulação mais precisa dos parâmetros metodológicos que orientaram a seleção dos entrevistados e a análise das entrevistas. O leitor é apresentado, entre os capítulos 2 e 7, a mais de cinqüenta personagens de perfis biográficos instigantes, mas não é informado o suficiente acerca dos critérios que especificamente nortearam a escolha desses indivíduos e famílias. Ademais, considerando-se que as transcrições que serviram de base para as análises e interpretações foram produzidas com base em entrevistas em situações de contato e convívio peculiares, entre 2001 e 2004, o leitor fica se perguntando a respeito dos parâmetros utilizados para interpretar as histórias 
em meio a essas interferências variadas. Nesse sentido, merece destaque positivo a clareza de Cabanes em certo momento (pp.401-5), além da avaliação crítica de Telles acerca das histórias familiares do sexto capítulo (p.309). Outro recurso que favoreceria a contextualização dos discursos seriam menções mais freqüentes aos anos de realização das respectivas entrevistas ou, como ocorre uma vez (p.291), ao momento a que se refere a formulação de argumentos sobre tal ou tal trajetória. E isso, aliás, porque é crucial nesta pesquisa a relação entre tempo biográfico e social. Particularmente no caso dos (ex-)militantes que protagonizam muitas das histórias, várias foram as mudanças no contexto político envolvendo, na cidade e no país, o Partido dos Trabalhadores dos sonhos - edesapontamentos - desses homens.

É crucial salientar que tais questões, contingentes, em nada ofuscam as potencialidades interpretativas do instigante objeto que os autores constroem ao longo da coletânea. Do entramado social emerge uma cidade múltipla queé, explicitamente, uma construção do sociólogo. É a São Paulo das tramas, que carrega em si, cifrado, um método que permite reconstituir de forma original as tramas de que ela se compõe.

FRAYA FREHSE é professora no Departamento de Sociologia da FFLCH-USP e pesquisadora associada do Núcleo de Antropologia Urbana da mesma universidade. 